\title{
Gallium In-Diffusion for the Fabrication of Lithium Niobate Optical Waveguides
}

\author{
Wen-Hung Huang, Student Member, IEEE, and Way-Seen Wang, Member, IEEE
}

\begin{abstract}
Gallium oxide used as a diffusion source for the fabrication of lithium niobate optical waveguides is presented. The optical waveguide properties are investigated and the behavior of the in-diffused gallium is characterized by the secondary ion mass spectroscopy. Single-mode single-polarization optical waveguides with low propagation loss at 632.8 and $1550 \mathrm{~nm}$ can be obtained. For reference, the diffusion constant and activation energy of the in-diffused gallium atoms are also obtained.
\end{abstract}

Index Terms-Directional coupler, integrated optics, lithium niobate $\left(\mathrm{LiNbO}_{3}\right)$, optical waveguide.

\section{INTRODUCTION}

$\mathbf{L}$ ITHIUM niobate $\left(\mathrm{LiNbO}_{3}\right)$ is known for its high electrooptical and nonlinear coefficients and has great applications in optical communication and nonlinear optics. In the meanwhile, with its excellent electrooptical and acoustic-optical properties, $\mathrm{LiNbO}_{3}$ is one of the favorite substrate materials for the application of integrated optics, especially for the integrated optoelectronic devices. In recent years, due to the similarity in crystal structure between sapphire and $\mathrm{LiNbO}_{3}$, the epitaxial growth of high-quality $\mathrm{GaN}$ on $\mathrm{LiNbO}_{3}$ substrate has been successfully demonstrated to implement the monolithic integration between the electronic and electrooptical devices [1]. In previous reports, gallium oxide $\left(\mathrm{Ga}_{2} \mathrm{O}_{3}\right)$ was used to fabricate the gallium-diffused waveguide in sapphire [2]. It was also reported that $\mathrm{Ga}_{2} \mathrm{O}_{3}$ codoped with $\mathrm{MgO}$ in $\mathrm{LiNbO}_{3}$ to grow $\mathrm{Ga}: \mathrm{Mg}: \mathrm{LiNbO}_{3}$ crystal is more resistant to the photodamage at short wavelength [3]. Following these ideas, we successfully fabricate the gallium-diffused optical waveguide on $\mathrm{LiNbO}_{3}$ substrate. To our knowledge, it is the first report for the gallium in-diffused $\mathrm{LiNbO}_{3}$ optical waveguide. The fabrication process can be more compatible with the GaN-related devices on $\mathrm{LiNbO}_{3}$ substrate for integrated applications. In this letter, the optical properties of the waveguide and the concentration profiles of the in-diffused gallium atoms are investigated. A $3-\mathrm{dB}$ coupler is also presented to demonstrate the application of the proposed waveguide for related devices.

Manuscript received April 30, 2007; revised July 20, 2007. This work was supported by the National Science Council, Taipei, Taiwan, R.O.C., under Contract NSC 95-2221-E-002-383.

W.-H. Huang is with the Graduate Institute of Photonics and Optoelectronics, National Taiwan University, Taipei 106, Taiwan, R.O.C.

W.-S. Wang is with the Department of Electrical Engineering, National Taiwan University, Taipei 106, Taiwan, R.O.C. (e-mail: wswang@cc.ee.ntu. edu.tw).

Digital Object Identifier 10.1109/LPT.2007.905182

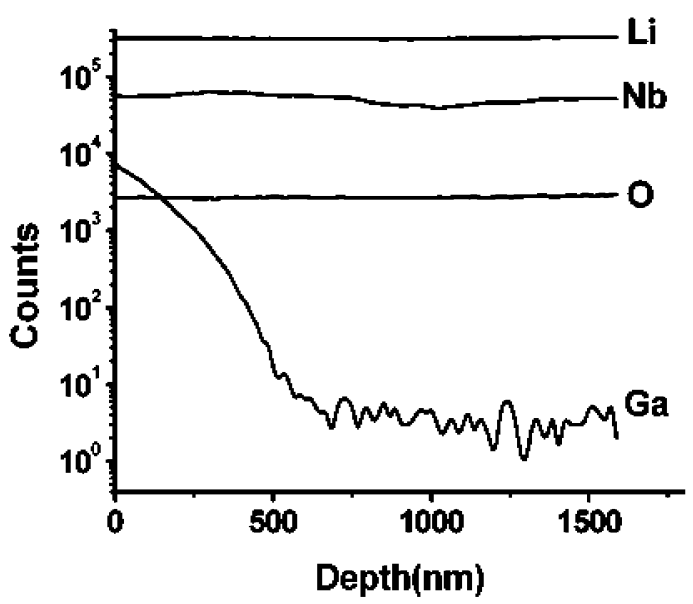

Fig. 1. SIMS analysis for the gallium in-diffused $\mathrm{LiNbO}_{3}$ substrate.

\section{EXPERIMENTAL RESULTS AND DISCUSSION}

\section{A. Waveguide Fabrication}

To fabricate the proposed channel waveguide on a y-cut $\mathrm{LiNbO}_{3}$ substrate, the channel waveguide pattern is defined by

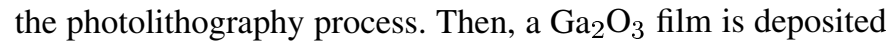
on the substrate by the RF sputtering technique. A 3-in $99.9 \%$ gallium oxide disk is used as the target in the RF sputter system. Before the sputtering process, the chamber is pumped down to a pressure of $4 \times 10^{-6}$ torr and then backfilled with argon gas. During the deposition process, the chamber pressure is controlled at 0.02 torr by a throttle valve and the argon flow rate is controlled at $8 \mathrm{sccm}$ by a mass flow controller. By the lift-off method, the $\mathrm{Ga}_{2} \mathrm{O}_{3}$ strip for the channel waveguide is then formed. The following diffusion process is performed in the furnace at $850^{\circ} \mathrm{C}-950{ }^{\circ} \mathrm{C}$ for $1.5-6 \mathrm{~h}$. Since the diffusion temperature is not high enough to induce a lithium out-diffusion layer that degrades the performance of the channel waveguide, the suppression technique [4] is not needed for the proposed gallium in-diffusion process. Finally, the end facets of the waveguide are polished by diamond films for optical characterization.

\section{B. Diffusion Behavior Analysis}

The waveguide is fabricated by depositing a $\mathrm{Ga}_{2} \mathrm{O}_{3}$ film of thickness $83 \mathrm{~nm}$ on a substrate of dimensions $15 \times 10 \times 1 \mathrm{~mm}$. The diffusion process is then performed at $800{ }^{\circ} \mathrm{C}$ for $0.5 \mathrm{~h}$. To study the relation between the refractive index change and in-diffused gallium atoms, secondary ion mass spectroscopy (SIMS) analysis is used to investigate the behavior of the in-diffused atoms. The result is shown in Fig. 1. In the range of 


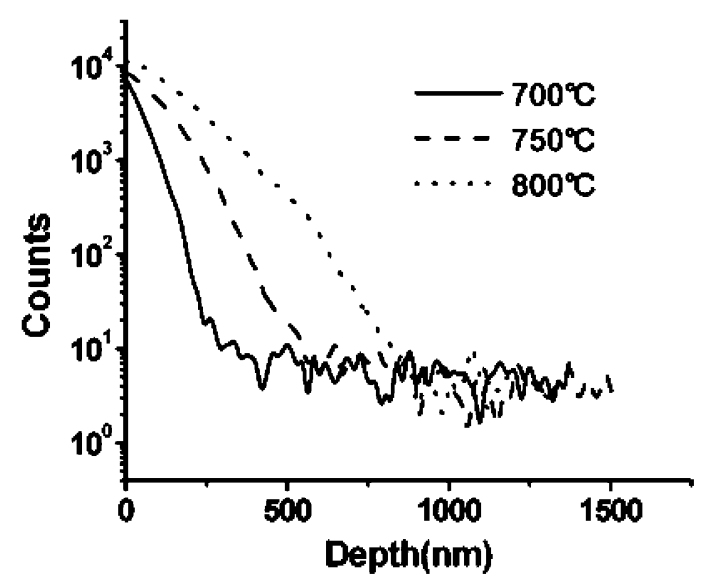

Fig. 2. SIMS analyses of concentration profiles of diffused gallium atoms at different temperatures for $1 \mathrm{~h}$.

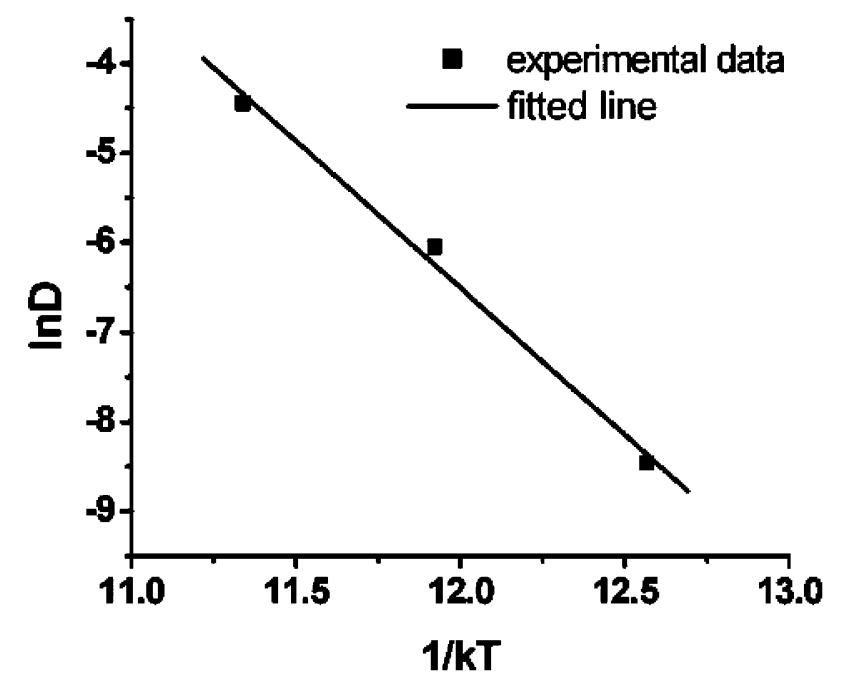

Fig. 3. Arrhenius plot $(\ln D)$ versus $1 / k T$ for the diffusion of $\mathrm{Ga}_{2} \mathrm{O}_{3}$ in a y-cut $\mathrm{LiNbO}_{3}$ substrate.

analyzed depth, the concentrations of the lithium, niobium, and oxygen atoms remain almost constant while the concentration of the gallium atoms shows a significant depth-dependent distribution, which implies that the index change is induced by the in-diffused gallium atoms. As a result, further analyses are performed for the distribution profile of the gallium atoms.

The concentration profiles obtained at different diffusion temperatures for a constant diffusion time $(1 \mathrm{~h})$ are shown in Fig. 2. Under these conditions, the $\mathrm{Ga}_{2} \mathrm{O}_{3}$ film is not completely depleted after the diffusion process and, therefore, according to the diffusion theory, the concentration profile is a complementary error function. Our experimental data show good agreement with the fitted curve and, therefore, the diffusion coefficient can be obtained. From the Arrhenius law, the diffusion constant and activation energy can be derived from the relation between diffusivity and temperature, as shown in Fig. 3. Good linear dependence between $\ln (D)$ and $1 / k T$ is observed, where $k$ is the Boltzmann constant. The diffusion constant and the activation energy are estimated to be $1.46 \times 10^{8} \mu \mathrm{m}^{2} / \mathrm{h}$ and $2.08 \mathrm{eV}$, respectively. Compared to titanium in-diffusion [5], the diffusion constant is similar while the activation energy is smaller for gallium in-diffusion. Consequently, the diffusion temperature and

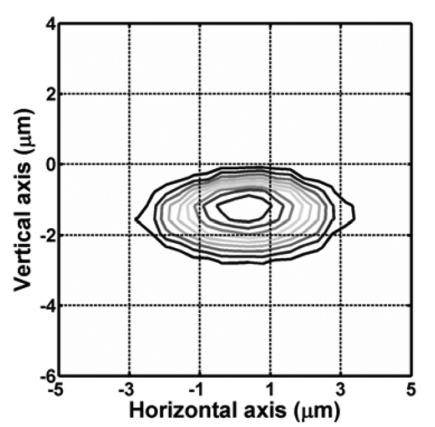

(a)

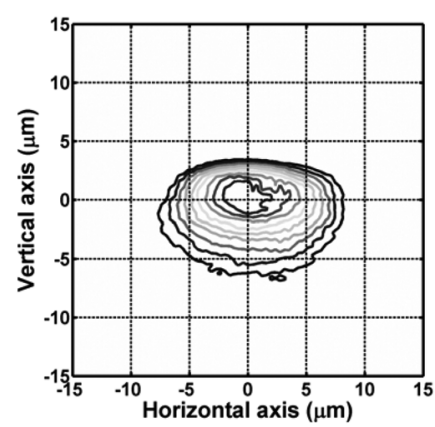

(b)
Fig. 4. Optical intensity contour patterns. (a) $632.8 \mathrm{~nm}$. (b) $1550 \mathrm{~nm}$.

TABLE I

FABRICATION PARAMETERS OF THE WAVEGUIDES FOR OPTICAL CHARACTERIZATION

\begin{tabular}{ccccc}
\hline $\begin{array}{c}\text { Wavelength } \\
(\mathrm{nm})\end{array}$ & $\begin{array}{c}\text { Strip } \\
\text { thickness width }\end{array}$ & $\begin{array}{c}\text { Strip } \\
(\mathrm{nm})\end{array}$ & \multicolumn{2}{c}{ Diffusion } \\
$(\mu \mathrm{m})$ & $\left({ }^{\circ} \mathrm{C}\right)$ & $\begin{array}{c}\text { Diffusion } \\
\text { time }\end{array}$ \\
\hline 632.8 & 83 & 4 & 900 & 1.5 \\
1550 & 83 & 7 & 950 & 1.5 \\
\hline
\end{tabular}

time for the proposed waveguide fabrication are relatively lower and shorter.

\section{Optical Characterization}

The measurement setup for the optical characterization is described as follows. An input laser light is coupled into the waveguide end through an optical lens. A polarizer is used to control the polarization of the input light. The output field is collected by an optical lens and then analyzed by a vidicon camera. By controlling the polarization of the input light, we found that only extraordinary wave can be guided in the proposed waveguide. It is an interesting point because in general, the metal-diffused optical waveguides in $\mathrm{LiNbO}_{3}$ substrate are able to support both TE and TM mode [6].

The output field intensity contours of the single-mode waveguides are shown in Fig. 4. The fabrication parameters of the waveguides for the optical characterization are listed in Table I. The dimensions of the samples are $15 \times 10 \times 1 \mathrm{~mm}$. The full-wave-half-maximum widths are 3.6 and $10.1 \mu \mathrm{m}$ at wavelengths 632.8 and $1550 \mathrm{~nm}$, respectively. Furthermore, the lithium out-diffusion layers are not observed in our samples just as expected. The propagation loss measured by the cut-back method is in the range of $0.2-0.9 \mathrm{~dB} / \mathrm{cm}$ at $632.8 \mathrm{~nm}$ and $0.5-0.7 \mathrm{~dB} / \mathrm{cm}$ at $1550 \mathrm{~nm}$, which is low enough for practical application. Similar results can be obtained by using the Fabry-Pérot method [7], which yields estimated propagation losses of 0.66 and $0.68 \mathrm{~dB} / \mathrm{cm}$ at 632.8 and $1550 \mathrm{~nm}$, respectively. The refractive index difference of the proposed waveguide is characterized by near-field analysis [8], which is able to derive the maximum index change and the index distribution profile from the near-field output pattern of the waveguide. For a planar single-mode waveguide at $632.8 \mathrm{~nm}$, the maximum index change is estimated to be $3.3 \times 10^{-3}$ while the index distribution profile is in the form of complementary 


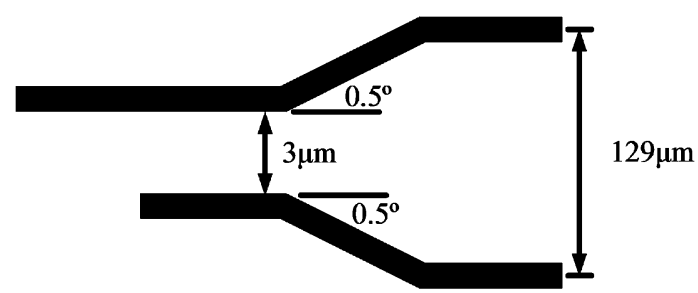

Fig. 5. Schematic structure of a 3-dB coupler.

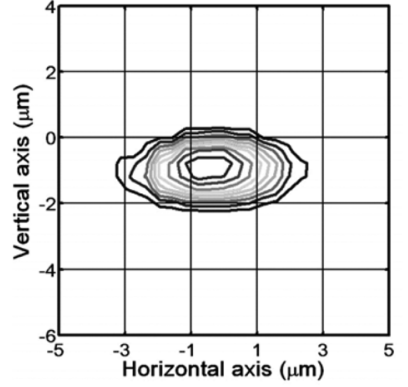

(a)

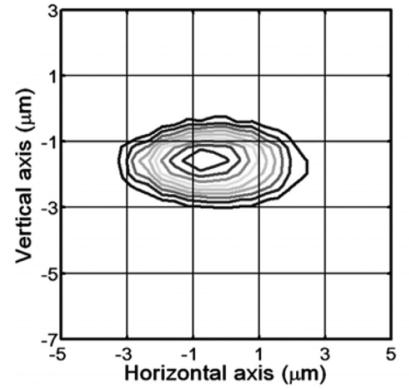

(b)
Fig. 6. Output intensity contour patterns of a 3-dB coupler launched with a laser of wavelength $632.8 \mathrm{~nm}$. (a) Original arm. (b) Cross arm.

error function, which is in accordance to the gallium concentration profile with the same distribution function.

To demonstrate the device application of the proposed optical waveguide, a 3-dB coupler, as shown in Fig. 5, is fabricated for a $\mathrm{He}-\mathrm{Ne}$ laser of a wavelength of $632.8 \mathrm{~nm}$. For single-mode operation, the waveguide width, the waveguide gap, and the separation between the two output branches are chosen as 4, 3, and $129 \mu \mathrm{m}$, respectively. To have a low bending loss, the bending angle is chosen as $0.5^{\circ}$. Experimental results show the coupling length is $1600 \mu \mathrm{m}$. The optical intensity field contours of the two output arms are shown in Fig. 6. Good confinement of optical fields can be seen.

\section{CONCLUSION}

A low loss, singly polarized $\mathrm{LiNbO}_{3}$ optical waveguide fabricated by gallium in-diffusion method is demonstrated. The diffusion behavior of gallium atoms in y-cut $\mathrm{LiNbO}_{3}$ substrate is investigated by SIMS analysis, and the diffusion constant and activation energy are obtained. Since the propagation loss of the proposed waveguide is smaller than that of the proton exchanged waveguide [9], it is a feasible alternative for single-polarization application. The maximum index change of the proposed single-mode planar waveguide investigated by near-field analysis is $3.3 \times 10^{-3}$ and index distribution profile is in the form of complementary error function distribution. In addition, a 3-dB coupler is fabricated to demonstrate the application of the proposed optical waveguide. Details of application in polarization-dependent system or monolithic electrooptical devices will be of great interest for future study.

\section{REFERENCES}

[1] S. M. Madison, W. Henderson, G. Namkoong, K. K. Lee, K. M. Patel, W. Alan, Doolittle, and S. E. Ralph, "Monolithic integration of electronic and electro-optical devices exploiting the $\mathrm{AlGaN} / \mathrm{GaN}-\mathrm{LiNbO}_{3}$ material system," presented at the Conf. Laser and Electro-Optics, Baltimore, MD, May 22-27, 2005, Paper CThD7.

[2] V. Apostolopoulos, L. M. B. Hickey, D. A. Sager, and J. S. Wilkinson, "Gallium-diffused waveguides in sapphire," Opt. Lett., vol. 26, no. 20, pp. 1586-1588, Oct. 2001.

[3] X. H. Zhen, R. Wang, W. S. Xu, Y. H. Xu, and L. C. Zhao, "Study on photodamage of $\mathrm{Mg}: \mathrm{Ga}: \mathrm{LiNbO}_{3}$ crystal wave-guide substrate," Opt. Mater., vol. 19, pp. 427-431, Jun./Jul. 2002.

[4] J. L. Jackal, "Suppression of outdiffusion in titanium diffused $\mathrm{LiNbO}_{3}$," J. Opt. Commun., vol. 3, pp. 82-85, 1982.

[5] S. Fouchet, A. Carenco, C. Daguet, R. Guglielmi, and L. Riviere, "Wavelength dispersion of $\mathrm{Ti}$ induced refractive index change in $\mathrm{LiNbO}_{3}$ as a function of diffusion parameters," J. Lightw. Technol., vol. LT-5, no. 5, pp. 700-708, May 1987.

[6] M. N. Armenise, "Fabrication techniques of lithium niobate waveguides," Proc. Inst. Elect. Eng., vol. 135, no. 2, pp. 85-91, Apr. 1988.

[7] R. Regener and W. Sohler, "Loss in low-finesse Ti:LiNbO 3 optical waveguide resonators," Appl. Phys. B, vol. 36, no. 3, pp. 143-147, Mar. 1985.

[8] F. Caccavale, P. Chakraborty, A. Quaranta, I. Mansour, G. Gianello, S. Bosso, R. Corsini, and G. Mussi, "Secondary-ion-mass spectrometry and near-field studies of Ti: $\mathrm{LiNbO}_{3}$ optical waveguides," J. Appl. Phys., vol. 78, no. 9, pp. 5345-5350, Nov. 1995.

[9] D. F. Clark, A. C. G. Nutt, K. K. Wong, P. J. R. Laybourn, and R. M. D. L. Rue, "Characterization of proton-exchange slab optical waveguides in z-cut $\mathrm{LiNbO}_{3}$," J. Appl. Phys., vol. 54, pp. 6218-6220, Nov. 1983. 